\title{
Fallopian Tube Neoplasm
}

National Cancer Institute

\section{Source}

National Cancer Institute. Fallopian Tube Neoplasm. NCI Thesaurus. Code C3032.

A benign or malignant neoplasm affecting the fallopian tube. Representative examples of benign neoplasms include papilloma, adenofibroma, and leiomyoma. Representative examples of malignant neoplasms include carcinoma, carcinosarcoma, and adenosarcoma. 